\title{
teorema
}

Vol. XXXII/3, 2013, pp. 35-58

ISSN: 0210-1602

[BIBLID 0210-1602 (2013) 33:3; pp. 35-58]

\section{Value and Epistemic Normativity}

\author{
David Owens
}

\section{RESUMEN}

Muchos autores han buscado fundamentar la normatividad epistémica en el valor del conocimiento, en el valor de la verdad o también en el valor de la agencia con éxito. Se propone aquí que las normas epistémicas derivan su autoridad del hecho de que es bueno para nosotros estar sujetos a las normas que gobiernan nuestras emociones doxásticas. En la medida que ignore que John ha robado mi bici, puedo esperar o temer que lo haya hecho pero no puedo estar complacido o enfadado porque lo haya hecho. El conocimiento (esto es: la satisfacción de las normas epistémicas) sirve a mi interés de estar en posición de que este hecho me complazca o me enfade, puesto que sirve a mi interés en estar sujeto a las normas que gobiernan tales emociones doxásticas.

PALABRAS CLAVE: creencia, conocimiento, emoción, pragmatismo, interés normativo, función, norma epistémica.

\section{ABSTRACT}

Many writers have sought to ground epistemic normativity in the value of knowledge or the value of truth or else in the value of successful agency. Here it is proposed that epistemic norms derive their authority from the fact that it is good for us to be subject to such norms. These norms serve our normative interests and in particular, they serve our interest in being subject to the norms that govern our doxastic emotions. So long as I am ignorant of whether John stole my bike, I can hope or fear that he did but I cannot be pleased or angry that he did. Knowledge (i.e. the satisfaction of epistemic norms) serves my interest in being in a position to be pleased or angry at this fact because it serves my interest in being subject to the norms that govern such doxastic emotions.

KeYwords: Belief, Knowledge, Emotion, Pragmatism, Normative Interest, Function, Epistemic Norm.

Believing has both a psychological and a normative aspect. My conviction that there is a snake before me has certain characteristic causes (e.g. an experience as of a snake) and certain characteristic effects (e.g. a feeling of fear and a rapid retreat). The characteristic causes and effects of belief I'll call the psychological role of belief. Believing is also subject to normative 
assessment and feeds into the normative assessment of emotions and actions: it may be rational to believe that there is a snake before me on the basis of my experience of a snake and rational to be afraid and to retreat given what I believe. I'll call this the normative role of belief. The normative role of belief specifies both how beliefs ought to be formed and how we ought to feel and act once they have been formed.

Are the psychological role of belief and the normative role of belief independent of one other? For example people tend to believe things that they wish to be true though they ought not to believe anything simply because they wish it to be true. Still it can't be a mere coincidence that you ought to believe there is a snake before you when you seem to see one (ceteris paribus) and that you tend to believe there is a snake before you when you seem to see one (ceteris paribus). Of course, the qualifying clauses are not identical — there are circumstances in which you won't believe what you ought to believe — but the parallel is striking all the same.

Perhaps not every aspect of belief's psychological role corresponds to some aspect of its normative role (viz. the case of wishful thinking) but the converse may still be true and I'll use the phrase 'characteristic psychological role' to refer to that aspect of belief's role which does roughly correspond to its normative role. The fact that there is such a role suggests that we are dealing with norms whose application is somehow connected to the fact that they tend to be obeyed. In this paper, I'll seek to explain that connection, to integrate belief's normative role with its psychological role and I'll do so by invoking a third feature of belief, namely the value of belief and in particular the value of believing to the believer i.e. the way in which believing serves the interests of believers.

Many would agree that it is a good thing to be able to form beliefs. Knowledge appears on the standard list of human goods and since belief is needed for knowledge, the capacity to form beliefs should be on that list too. For the moment, let's assume that belief and knowledge are a good thing, leaving the source of their value for later investigation. But does the value of belief have anything to do with the normative and psychological roles of believing?

Take belief's normative role. Many writers maintain that all forms of normativity must be grounded in a value of some sort. Where I have a genuine reason to form beliefs in accordance with the evidence (rather than my wishes) there must be something to be said in favour of forming my beliefs in this fashion, some desirable feature of rational belief formation. What basis for epistemic normativity could there be other than the interests of believers, other than the fact that beliefs of a certain sort are good for them?

Now consider belief's psychological role. We need to explain why phenomena with the characteristic causes and effects of beliefs exist. One way of doing so is to suppose that phenomena with the psychological role characteristic of belief are good for the creature that enjoys them. Various mechanisms 
may connect the value of a phenomenon to its existence: perhaps the creature realises that they have an interest in belief and forms beliefs with a view to furthering that interest, perhaps some social or biological mechanism is at work. Either way, the value of belief would help to explain the existence of belief, would help to explain the fact that there are psychological states and processes with the causes and effects characteristic of beliefs. We thereby integrate the psychological and the normative role of belief by way of an hypothesis about the value of belief.

In this paper, I shall be exploring the idea that believing has a function. Belief performs its function when it takes a certain form, a form that tends to serve the interests of the believer and thereby explains the characteristic psychological and the normative role of belief. I say 'tends to' because there might be particular cases where the relevant form of believing would not serve the believer's interests. For example, believing truly rather than falsely might have nothing to be said for it on some occasions. Nevertheless provided believing truly generally does serve the creature's interests and serves them better than any other plausible function, the hypothesis that believing truly is the function of belief will best explain the characteristic psychological and normative role of belief.

I shall examine several proposals as to what the function of belief is before presenting my own. In the first section, I consider the view that the function of belief is to represent the world correctly, that verisimilitude is the value served by belief. In the second section, I ask whether the function of belief is to ensure successful agency; then in section three I argue that the function of belief is to regulate our emotional lives. In the final section, I urge that subjection to the norms that regulate our emotional lives is itself of value, and that the interest served by belief (that which specifies its function) is a normative interest, namely an interest in being subject to those very norms.

\section{Alethic CONCEPTIONS OF BELIEF}

Here is a norm of belief formation:

Correctness: Believe that $\mathrm{p}$ only if $\mathrm{p}$ is true. ${ }^{1}$

Correctness captures at least part of the normative role of belief. For example, it differentiates merely imagining that $\mathrm{p}$ from believing that $\mathrm{p}$ and imposes a requirement of consistency on belief. $^{2}$ How might we embed Correctness in our psychology? 
Judgement: To judge that $\mathrm{p}$ is to entertain the thought that $\mathrm{p}$ when the question as to whether $\mathrm{p}$ arises and when one is trying to entertain a thought that answers this question correctly (i.e. in accordance with the above norm).

Belief: To believe that $\mathrm{p}$ is to be disposed to judge that $\mathrm{p}$ if the question as to whether $\mathrm{p}$ arises.

Correctness governs both judgement and belief in that both involve either an attempt or a disposition to conform to this norm.

For Shah and Velleman 'judgement' is a mental act (an occurrence) that (in a rational person) generates a belief (a disposition) with the same content. Both judgement and belief have two aspects: psychological and normative. As to the normative they are both governed by Correctness. As to the psychological, they are both 'regulated for truth' i.e. 'tend to be formed, revised, and extinguished in response to evidence of p's truth'. Shah and Velleman connect these two aspects by way of the idea that a believer aims at having correct beliefs, though they allow for other sub-intentional forms of regulation [Shah and Velleman (2005), pp. 497-9; Velleman (2000), pp. 252-4]. Guidance mechanisms other than intentional effort are indeed required but the nature of the mechanism won't matter for present purposes. ${ }^{3}$ The important point is that the presence of some guidance mechanism ensures at least a rough fit between the normative and the psychological roles of belief. To arrive at a functional explanation of belief, we need one further element: we need a value that both underwrites the normative authority of Correctness and explains why it is embedded in our psychology.

Truth is a plausible candidate. Given that you are going to have a belief on a certain matter, isn't it better that the belief in question be true rather than false? In a particular case there may be various advantages to having a false belief, advantages that might outweigh the value of truth but isn't there still something to be said in favour of having a belief that is true? Doesn't truth have a value (intrinsic or instrumental), a value that the norms of beliefformation serve to protect and promote? ${ }^{4}$ And even if it doesn't always have value (e.g. the truth on a trivial matter) doesn't it generally? If so, that would allow us to suppose that tracking the truth was the function of belief. Further questions arise: is the value of truth a matter of personal value, of true belief's being better for the believer (or someone else) than false belief? Or is truth rather an impersonal value, a good that need not be good for anyone at all? I'll assume for the sake of argument that truth has a value of some sort and that Correctness can be grounded in the value of truth. This granted other worries remain.

As William James observed, Correctness does not require us to form beliefs: you could conform to it by believing nothing at all [James (1956), pp. 
17-9]. One might think that the laws of logic will generate some beliefs, since they give us principles of reasoning and inference, but that is an illusion [Harman (1973), Chapter 10]. For example, if we find ourselves with inconsistent beliefs the logician tells us to do something about it but not what to do about it: you can resolve inconsistencies in several different ways, you can abandon your premises rather than accept their implications and so forth. We are not yet being told what to believe.

Is this a problem? Might epistemic norms specify necessary but never sufficient conditions for rational belief? Suppose I feel an impulse to entertain the thought that $\mathrm{p}$, an impulse that may be non-rational or else might reflect non-epistemic reasons, reasons of the sort that also guide mental processes other than belief formation. Still won't I entertain the thought that $\mathrm{p}$ in the mode of judgement or belief provided that, in entertaining it, I try to conform to Correctness? In aiming to conform to Correctness, I attend to evidence, to indications of truth (or rather of falsity). Isn't that enough to ensure that the result of my thinking is a judgment or a belief?

The problem is that many attitudes other than belief and judgement satisfy this specification. Suppose judgement is 'thought regulated for truth' and that to 'regulate thought for truth' involves trying to produce truthful thought. In trying to $\phi$, one need not think that one will succeed or even that success is likely; one need think only that there is some chance of succeeding, enough to make it worth a try. So one can regulate thought in an attempt to make it conform to Correctness without thinking that the result will be true or even likely to be true, provided one knows enough to have a stab at it. Thus whilst aiming at truth involves being sensitive to evidence, it need not involve being sensitive to evidence in anything like the way in which judgement and belief are sensitive to evidence [Owens (2003)].

The underlying point is quite general. I do not count as having (intentionally) written down a particular word, whether correctly or incorrectly, unless I at least tried to spell that word correctly. Writing 'assessment' was not something intentionally did unless one of my aims was to write down a word with the correct number of 's's. But how hard I should try to spell 'assessment' correctly is a function of exactly why I wanted to write it down. If time is short and I must issue a written warning that you are about to be assessed, it would be silly for me to worry too much about precisely how many 's's the word contains. My goal of good spelling must be balanced against the other goals I am trying to achieve and here correct spelling may count for rather little. All things considered, it may be sensible for me to write the word at a speed that makes it rather unlikely that I shall achieve my goal of spelling it correctly. This prudent haste is perfectly consistent with the fact that, whether I spelt it correctly or not, I count as having written it at all only because I was trying to spell it correctly. 
Similarly the fact that one is aiming to think a certain thought only if that thought is true does not tell us very much about how much trouble one should go to in order to confirm that the thought is true. For example, suppose one is trying to think truthfully in order to participate in a quiz. In a quiz, one answers that $\mathrm{p}$ with the aim of answering correctly but, given the context, it would be perfectly appropriate to make an educated guess. If the wider purposes that lead one to seek the truth are less frivolous, a much higher standard might be appropriate. But there can be no guarantee that such a standard would match that usually required for reasonably judging or believing that p. It all depends on the nature of the activity. ${ }^{5}$

Some doubt that guessing is a propositional attitude [Shah and Velleman (2005), p. 498 n. 7]. Perhaps one could guess the number of planets for the sake of answering the question though one had no views of any kind about the number of planets. But often one's guesses, internal and external, will be an expression of one's suspicions and suspicion surely is a propositional attitude, an attitude governed by Correctness. To suspect that O. J. murdered his wife is to make a mistake should he be innocent (however justified the suspicion and reasonable the error). ${ }^{6}$ Suspicion comes out of the same box as doubt, hope and fear. Both hope and fear that $\mathrm{p}$ are shown to be mistaken or erroneous once $p$ turns out to be false. Conversely, if you doubt that $\mathrm{p}$ when $\mathrm{p}$ is true, you have made a mistake even if you don't go so far as to believe that not-p. Now the evidence required for reasonable suspicion (or fear or hope) that p clearly differs from that required for reasonable belief in $\mathrm{p}$ and the evidence required for reasonable doubt that $\mathrm{p}$ clearly differs from that required for reasonable belief in not-p. So Correctness fails to capture the normative role of belief.

Might we strengthen Correctness by setting a more demanding goal? How about:

Knowledge: Believe that $\mathrm{p}$ only if your belief would constitute knowledge of $\mathrm{p}$.

There is no requirement that we know what we guess, suspect, etc. On the contrary ignorance is a presupposition of guessing, suspecting, hoping and fearing. So perhaps believing that $\mathrm{p}$ is thinking that $\mathrm{p}$ whilst attempting to conform to the knowledge norm. If so, we can after all capture the distinctive normative character of belief by specifying only necessary and not sufficient conditions for rational belief formation.

I agree that Knowledge is a norm that applies uniquely to belief (and belief-involving states). You can't think it reasonable to believe that $\mathrm{p}$ if you take yourself to be ignorant of whether p [Owens (2000), pp. 40-1]. Furthermore, this norm indicates a plausible value. Isn't knowledge pro tanto better than ignorance, at least where it is important to have some view on the mat- 
ter? This may be denied but let's allow for now that Knowledge is a norm grounded in a genuine value and one which captures the distinctive normative role of belief. Still, depending on our theoretical ambitions this may not be a very satisfying result for knowledge is a value whose content can be specified only by reference to the satisfaction of the very epistemic norms whose authority we are seeking to ground in that value.

It is at least arguable that verisimilitude is not a normative notion. Can't we grasp what it would be for a belief to be true (a painting to be accurate, an experience to be veridical) without assuming anything about whether and when one ought to form beliefs (paint paintings, have experiences)? If so and if verisimilitude is a value then it is a value that can be specified without using normative notions. For that very reason Correctness seems well placed to explain the content of other norms of belief formation. For example, the requirement that we have at least some evidence for what we believe is down to the need to ensure that our beliefs are true, where truth can be understood independently of the norms of evidence.

The problem with Knowledge is this: knowing that $\mathrm{p}$ involves having a belief in p to which you are entitled. Attempts to replace this 'justification' condition for knowledge with something non-normative (reliability, counterfactual connection, etc.) have consistently failed. Is this a problem? In the last section, I shall argue that it isn't but many of those puzzled by epistemic normativity will wonder how we can explain why certain epistemic norms govern the formation of belief by supposing that belief is required to be knowledge, when knowledge involves the satisfaction of those very epistemic norms.

Both Correctness and Knowledge connect our epistemic norms to something that is plausibly of value: it is because we value truth over falsity, knowledge over ignorance that we feel our beliefs ought to be based on evidence. But more needs to be said. We can't explain the content of our epistemic norms simply by setting up truth or knowledge as a goal; we can't say that the point, purpose or function of belief is just to represent things as they are. To discover what is distinctive about belief, we must ask why people form beliefs, why they should want to get at the truth in this particular way. ${ }^{7}$

\section{PRAgMATIC CONCEPTIONS OF BELIEF}

In addressing these questions, Edward Craig tells us that

Fortunately there is a firmly fixed point to start from. Human beings need true beliefs about their environment, beliefs that can guide their actions to a successful outcome [Craig (1990), p. 11]. 
So the function of belief is to be true and the value of true belief lies in its motivating successful agency, agency that achieves its objectives. Craig goes on to argue that true beliefs constituting knowledge are precisely those most likely to guide action to a successful outcome. So we should add that the function of belief is to constitute knowledge of the truth and the value of knowledge is to be found in its role in motivating action.

This suggestion about the source of epistemic normativity has indeed been an intellectual fixture, at least since the advent of Pragmatism. It is endorsed by American Pragmatists like Pierce, James and C.I. Lewis, British Pragmatists like Ramsey and Braithwaite and by many more recent writers. ${ }^{8}$ For example, in the debate between those who think we can state the norms of theoretical reason in terms of Bayesian degrees of confidence and those insist that we must (also?) employ notions of knowledge or 'all-out' belief, the objective is usually taken to be the explanation of rational agency. And the same applies within the recent literature on 'pragmatic encroachment'.

As to the latter, Fantl and McGrath maintain that 'the importance of the concept of knowledge' resides in the fact that

it sets a meaningful lower bound on strength of epistemic position: your epistemic position regarding $\mathrm{p}$ must be strong enough to make it rational for you to act as if p is true [Fantl and McGrath (2007), p. 581],

while Stanley and Hawthorn claim that:

Where one's choice is p-dependent, it is appropriate to treat the proposition that $\mathrm{p}$ as a reason for acting iff you know that p [Stanley and Hawthorn (2008), p. 578].

The differences between these formulations will not matter here; I shall treat them both as characterising knowledge by citing a norm that connects knowledge with agency. If we also assume that something like Knowledge is correct, we can derive a claim about belief, namely

Pragmatism: We are entitled to believe that $\mathrm{p}$ iff we are entitled to act as if $\mathrm{p}$ is true (or take $\mathrm{p}$ as a reason for action).

I want to highlight two attractions of Pragmatism. The first is that it connects belief to what many take to be the ultimate source of any form of normativity, namely our ability to produce valuable states of affairs by means of our agency. On this view, false and ignorant belief are bad because they undermine our ability to pursue familiar goods like pleasure, beauty and so forth. The feature of an agent that enables them to pursue those goods successfully is the ability to make the world satisfy the desires or fulfil the intentions on 
which they act. Such a match is the just inverse of truth and no more requires normative notions for its specification than does truth itself.

A second attraction of Pragmatism is that it seems to do a good job of differentiating belief from the other propositional attitudes governed by Correctness. To be entitled to suspect (or hope or fear) that $\mathrm{p}$ is not to be entitled to act as if $\mathrm{p}$ is true. In certain contexts, one might be entitled to act on one's suspicions or guesses but, I take it, the Pragmatist claim is that one is always entitled to act on one's belief, to act as if one's beliefs are true, whatever the context. Thus the norms governing belief in $\mathrm{p}$ will be those whose satisfaction always makes it sensible to act as if $\mathrm{p}$ were true. We now have an answer to our earlier question: what is the point of trying to get at the truth by forming beliefs, by coming to know the truth? Belief and knowledge provide a basis for making decisions about what to do.

It might be wondered whether we really need 'all-out' beliefs in order to take decisions. Couldn't we manage with Bayesian degrees of confidence in the relevant propositions, without seeking to divide those propositions into those that we know and those we don't? What practical purpose is served by trying to set an evidential threshold above which one may believe that $\mathrm{p}$ and below which one may not? Why not just proportion one's belief to the evidence, proportion one's willingness to behave as if $p$ to the degree of one's belief in p and act accordingly? Isn't that how we determine what odds to accept in a betting situation?

The Pragmatist answer is familiar. ${ }^{9}$ We can't keep track of the evidence for and against the innumerable propositions whose truth might matter to us. At some point we need to cease deliberation, close the books on a given matter, throw away much of the evidence (so we don't have to store it), take a view and act accordingly. Even where our view takes the form of a judgement with a probabilistic content it will still be an all-out belief, not a Bayesian level of confidence. ${ }^{10}$ In the eyes of the Pragmatist we make up our minds about what to think by forming beliefs for much the same reason that we set ourselves to do something by forming an intention to do it: to act effectively, often we must cease to deliberate before the time to act arrives and take a view both about how things are (or are likely to be) and about what we ought to do in the light of this. The precise point at which we should make up our minds about how things are (at which the evidential threshold for rational belief has been reached), like the precise point at which we should settle what to do, will be fixed by the need to ensure successful agency.

The charms of Pragmatism may be illusory. Let's start with the second attraction. Is the evidential threshold for knowledge (and so rational belief) really tied to the requirements of rational agency in the way the pragmatist suggests? It is not so clear that it is always rational to act as if p simply because you know that p. In particular, this may not be rational in some cases where (a) the costs of acting as if $p$, should $p$ turn out to be false, are substan- 
tial or (b) the benefits of acting as if not-p should not-p turn out to be true are substantial. If so the Pragmatist cannot use Knowledge to explain the function of belief.

I have parked my car on the street outside taking the amount of care a reasonably conscientious citizen would to park legally. When I enter the house, my partner informs me that the police have been towing cars on the street this week. Before being told of this, I took myself to know that my car was parked legally, that is, I took myself to have evidence sufficient to justify my believing this. And, we may suppose, I did know. But hearing my partner's words, I reluctantly go out and recheck the position of my car and the relevant parking notices. Is this an implicit admission that I no longer know that my car is legally parked (at least until I have completed the checks) because my belief is no longer justified? ${ }^{11}$

Being reluctant to check, I might say to my partner 'I know I'm properly parked' and they might reply 'Yes I agree but it is still worth checking'. That sounds as if my partner is agreeing that I do know and thus agreeing that they can learn from me how the car is parked whilst also suggesting that here it would not be sensible to act on our knowledge since the costs of being wrong on this point are substantial and the check can easily be made. Suppose my partner instead says 'But do you really know the car is properly parked?' Now it sounds as if I am being invited to abandon my belief and to do so because it has become unjustified. But this isn't the only interpretation available. Perhaps my partner is highlighting the possibility that my belief is false, a possibility on which I must now focus for practical rather than epistemic reasons.

Our car example is one in which I am sensible not to act on my belief that $\mathrm{p}$ because the costs of being wrong are substantial. Similar issues are raised by cases in which I risk missing out on a considerable, though unlikely, benefit if I act on my belief. Suppose someone offers to pay me ten million pounds in return for a stake of ten pence if it turns out that I was not brought up a Catholic. I know that I was brought up a Catholic and much of the rest of what I know about myself would make little sense were I not. Nevertheless I might reasonably accept the bet [Hawthorne (2004), p. 176]. Can the mere fact that I have been offered this bet render one of my securest convictions unjustified?

On the one hand, it would sound odd for me to confess ignorance of which religion I was raised in because it is silly to miss out on this bet. On the other hand, as I place the bet, I might say to myself 'Well I suppose I might be wrong about which religion I was born into' and then it would be slightly strange to add 'but I do still know'. There is something awkward about describing yourself as acting on an assumption that you know to be false but the awkwardness may just be the awkwardness of explicitly acknowledging the possibility of error in a context in which you also claim 
knowledge. 'I know that p though I'm not absolutely sure that p' jars [Unger (1975), p. 99], as does 'I know that p though I might be wrong' but we shouldn't infer that one who takes themselves to know cannot sensibly acknowledge their own fallibility. On the contrary, rationality requires such an acknowledgement from us all and rationality permits us, on occasion, to act on it by not assuming in our practical deliberations things we take ourselves to know.

In response to these points, the Pragmatist might weaken his position thus:

Default Pragmatism: To be entitled to believe that $\mathrm{p}$ is to be entitled to use $\mathrm{p}$ as a default assumption in one's practical reasoning. ${ }^{12}$

In answering any question (whether practical or theoretical) we must take various things for granted. The Default Pragmatist suggests that there are some propositions that we are entitled to take for granted in answering any given question unless we see a special reason to do otherwise. Those propositions are the ones we are entitled to believe. And the propositions we do believe are those we actually do take for granted unless an alarm goes off. Default Pragmatism would allow that someone can fail to act as if $\mathrm{p}$ once an alarm goes off, whilst continuing to believe that p, provided they continue to be disposed to act as if $\mathrm{p}$ (without further consideration of whether $\mathrm{p}$ ) when no alarm is sounding. Once the alarm has gone off one presumably considers what to do on the basis of other beliefs (some of which concern evidence for or against the truth of p), these other beliefs being used as default assumptions in the present context. That's what happens when one decides to purchase the lottery ticket or to check one's parking.

I doubt that Default Pragmatism constitutes an adequate characterisation of belief. First, why shouldn't the same be said of other propositional attitudes? For example, a lawyer may have no views about her client's innocence but she is entitled (and indeed obliged) to assume his innocence in her practical (and other) reasoning, unless the 'I'm no longer on the job' light is on. And it can be no objection that the significance of the light is practical rather than theoretical since the same is true in the car and lottery examples. It may be objected that our lawyer's acceptance of this proposition is not subject to Correctness but why can't be same point be made with attitudes like suspicion which are? Suppose I'm in a quiz situation. Shouldn't I treat as true all those propositions that I suspect to be true unless and until the 'quiz is over' light goes on?

Perhaps one acts on one's beliefs in a much broader range of contexts than on one's acceptances or one's suspicions. Three worries about this. First, it makes the difference between beliefs and suspicions etc. out to be a matter of degree: it is just that we are both inclined and entitled to place greater reliance on the former. The idea that there is a categorical difference between 
knowledge and ignorance - the idea that Fantl and McGrath, Stanley and Hawthorn etc. seemed to be trying to capture - has now escaped us. Second, we need some way of determining which set of contexts is relevant to the practical significance of belief as opposed to suspicion etc. In how wide a range of contexts must it be reasonable for us to act as if p before we can reasonably believe that p (rather than merely suspect it)? It is unclear how we should go about answering this question.

My final worry about Default Pragmatism is that it appears coherent to suppose that attitudes other than belief might play the foundational role meant to be distinctive of belief. In Part Three of the Discourse on the Method Descartes proposes that once we've abandoned most (or all) of our beliefs in the face of his sceptical argumentation, we should conduct our practical reasoning on the basis of probable opinions, until such time as we are entitled to get our beliefs back. ${ }^{12}$ Descartes agrees that the abandonment of conviction has profound and painful psychological consequences (see below) but these do not include the end of practical deliberation. We can act without conviction, even probabilistic conviction.

On any form of Pragmatism this last suggestion is incoherent and Cartesian scepticism a charade because these 'opinions' just are the agent's beliefs under a new name. Hume thought Cartesian scepticism a charade because he doubted that we could decide to abandon our convictions [Hume (1975), pp. 149-50]. But, if the Pragmatist is right, the problem is not so much Descartes's optimism about our powers of doxastic self-control as his conceptual confusion about belief. That seems too strong. Suppose (pace Hume) that we could reject, or put on ice, our whole worldview. Why couldn't we still treat a set of propositions as default motivators in a range of contexts without thereby reacquiring our convictions?

In this section, I have been focused on the Pragmatist's claim to be able to differentiate belief from other attitudes governed by Correctness. In the next I'll query Pragmatism's other attraction, the idea that belief's role in the guidance of agency is the ultimate ground of epistemic normativity because it is the source of belief's value. The psychological role of belief includes the regulation of our emotional life as well as the instigation of action and I doubt that the norms governing our emotions are based on the need to act successfully. If norms of apt feeling are grounded in value, it is in value of another sort.

\section{BELIEF AND THE PASSIONS}

In this section, I'll argue that the evidential threshold at which it becomes rational to believe and so to claim knowledge of $\mathrm{p}$ is not the threshold at which it would be rational to act as if $\mathrm{p}$ is true; rather it is the point at 
which it would be appropriate to have certain emotional attitudes towards p. This suggests that the function of belief is to regulate our emotional life rather than our agency, a suggestion I'll pursue in the final section.

In respect of their connection with belief and knowledge, emotions come in at least two varieties. More numerous are those with the following feature: a subject experiences them only if there is some proposition such that (i) the emotion in question takes that proposition as its object and (ii) at least in so far as he is rational, the subject has the relevant emotion only because he takes himself to know the proposition in question. Thus to be angry is to be angry at the truth of some proposition, a proposition whose truth one takes oneself to know. Perhaps I am angry because I believe that John stole my bike. Here there is a proposition I take myself to know, a proposition specifying the object of my anger and I can't be angry unless there is some such proposition. ${ }^{14}$

Call the emotions of which (i) and (ii) must be true the doxastic emotions. Doxastic emotions include regret, resentment, horror, disgust, fury, sorrow, embarrassment, disappointment, shame, as well as delight, gratitude, pleasure and pride. Of course one's anger may be misdirected; John may not have stolen my bike. And even if John did steal my bike, I may not know this; perhaps I've been told by an informant who, though credible, is only repeating a vague rumour that nevertheless turns out to be true. In that case it would be wrong to say that I am angry that John stole my bike since I cannot be angry about things of which I am ignorant. But it remains true that I am angry only because I take myself to know that John stole my bike. I am angry in the belief that John stole my bike. ${ }^{15}$ Hence anger is a doxastic emotion. ${ }^{16}$

The basic non-doxastic emotions are hope and fear together with their variants worry, terror and so forth. These emotions are like their doxastic cousins in that they take a propositional object; if one is feeling hopeful, there must be something one hopes is the case. Furthermore, they too are governed by Correctness; a false hope (or fear) is a mistaken hope (or fear). But one is merely hopeful (rather than joyful) or fearful (rather than devastated) precisely because one does not take oneself to know the final outcome. Hope and fear exclude knowledge. Once I realize that the prize is going to someone else, I can no longer hope to win it. Nor can I hope to win it once it is revealed that I have won it.

Both doxastic and non-doxastic emotions come in degrees: joys and regrets, hopes and fears are all stronger or weaker and all more or less intense. But this similarity conceals an important difference. The strength of a nondoxastic emotion varies in two dimensions, the strength of a doxastic emotion in only one. Consider hope. Gordon tells us that to hope that you'll win the prize you must (a) be in doubt as to whether you have won it and (b) wish to win it [Gordon (1987), Chapter 4]. But hoping to win is a matter of being in some degree hopeful that you will win, of having hopes of winning that might be dashed; mere doubtfulness about whether you will in fact win seems 
less than hopeful. We need a more positive epistemic attitude, something like the suspicion that you'll win. ${ }^{17}$ Now your suspicion and your wish may vary in intensity independently of one another. The more you wish to win, the more you hope that you will win. In this respect hope is like joy: the more you want the prize, the more you'll enjoy getting it. But the strength of your hopes also varies as your suspicion that you'll win waxes and wanes. As the evidence that you will win piles up your hopes rise, as doubts intensify your hopes fade. There is no corresponding dimension of variation in the case of joy. For joy there is an evidential threshold: either the evidence (in your eyes) fails to establish that you have won in which case joy is out of the question or else it succeeds in which case you experience joy in the degree made appropriate by the desirability of its object.

Someone can be angry or happy at the fact that p, or proud of it, or grateful for it, only if they know that p. This suggests the following hypothesis: often we want to know whether p in order to fix our emotional bearings, to avoid having our feelings baffled by ignorance. In eliminating uncertainty we learn how to feel, not just how to act. Emotional bafflement (as well as practical uncertainty) renders doubt painful and drives inquiry. True, we might sometimes prefer to stick with those emotions - hopes and fears - that presuppose uncertainty rather than learn the truth. But very often we're anxious to discover whether we have a fatal illness and not just so we can make the appropriate arrangements. We want to know how to feel about the situation.

The Pragmatist might agree with all this whilst insisting that these roles are complementary: belief both sets our emotional bearings and guides our practical deliberation. But, in Descartes' eyes, these two things can come apart.

So serious are the doubts into which I have been thrown as a result of yesterday's meditation that I can neither put them out of my mind nor see any way of resolving them. It feels as if I have fallen unexpectedly into a deep whirlpool which tumbles around me so that I can neither stand on the bottom nor swim to the top [Descartes (1984), p. 16].

This feeling of disorientation is not a matter of being unable to decide what to do. Reason still guides Descartes' practical deliberations. His sense of being unmoored comes from elsewhere and so belief's essential function seems not to be practical. The Pragmatist might concede even this whilst insisting that, where belief does have practical significance, the standards of reasonability for belief are set by practical requirements. To test this suggestion we must consider cases in which feeling as if $\mathrm{p}$ would be sensible though acting as if $\mathrm{p}$ would not and vice versa.

We saw earlier that, were the line between knowledge and ignorance of $\mathrm{p}$ directly tied to whether we are in a position to act on p, that would have some rather implausible consequences for rational belief ascription. These points ex- 
tend to the doxastic emotions. For example, I can feel proud that I was raised a Catholic, or ashamed for that matter, only if I know that I was raised a Catholic. If I don't know this, whilst I can entertain hopes or fears on the matter, I can't feel pride or shame. Yet pride or shame won't be impossible just because I have been offered the bet. Pride and shame need not come and go in response to such offers, rather they are part of a more permanent background, dependent on relatively stable convictions which structure our emotional lives.

Now imagine that I am rather proud to own such a fine car, the very car I parked outside the house. On this occasion my partner informs me some time after I have arrived in the house that the police are confiscating illegally parked cars and were doing so in our street only last week. Must I cease to take pride in my car until I have checked that no such confiscation has taken place? Should I be gripped by fear for my social status? A sober person would rather judge that it is sensible to check how the car is parked and then calmly leave the house, convinced that their car is still there. Similarly, I can accept the bet on whether I am a Catholic without experiencing troubling doubts about my social identity.

I don't deny that being offered the bet or being told of the ticketing can engender doubts. One might feel a little relieved to find that one's car is safely parked or to have one's religious upbringing confirmed by further inquiry. What I deny is that checking the car or taking the bet is rationally permissible only in so far as one entertains such doubts. Even a slight doubt about a crucial matter can be deeply disturbing. ${ }^{18}$ Does it make sense to require that anyone who checks or bets on a crucial matter also feel disturbed in this way? It is because such doubts are not required of us that we often check our cars and bet on unlikely outcomes with equanimity.

Pride and shame are tied very directly to our sense of self-worth and thus to our well being but what is true of pride (or shame if I feel bad about driving a status symbol) applies equally to anger, embarrassment, sorrow, joy, gratitude, disappointment, disgust, and much of the rest of our emotional lives. We are intensely curious about all manner of things and to be ignorant of the truth about them is painful. If I'm right, we can allow for the possibility of their falsehood in our practical deliberations without this shattering consequence. And we do.

\section{EPISTEMIC NORMS AND NORMATIVE INTERESTS}

The argument of the last section established that epistemic norms track the aptness of our doxastic emotions much more closely than they track the rationality of our intentions or actions. Since we are looking for a functional explanation that traces both the normative and psychological role of belief to some valuable phenomenon, the obvious candidate is the enjoyment of doxastic 
emotions. We first hypothesize that the function of belief is to constitute knowledge, just as the Knowledge hypothesis suggests. Then we explain the value of knowledge by reference to its involvement in our emotional engagement with the world. On my hypothesis, the difference between knowledge and ignorance matters to us because the capacity to have doxastic emotions matters to us and we possess that capacity only in so far as we enjoy knowledge.

A question now arises. There is no mystery about the value of successful agency and thus about the worth of the things that facilitate it. On occasion we may benefit from acting on false or at least over-hasty assumptions but in general things will go better when we base our plans on knowledge rather than on ignorance. Is the value of apt emotions so obvious? So long as life is good, the menu of apt emotions adds relish to the dish. Once our fortunes turn, appropriate emotional engagement with them makes life worse rather than better. My friend dies and I am devastated. Clearly I must register this misfortune in my plans: no point going to see her if she won't be there. But wouldn't a quite inappropriate emotional indifference be better, at least better for me? Won't my remaining friends feel more sorry for me should I feel my loss and less sorry were I indifferent to it?

What I am supposing to be of value here is not the experience of an apt grief but rather the ability to react (both positively and negatively) to my friend's fate, the capacity to engage emotionally with this aspect of the world. To grasp the point, let's first set aside several things that the phrase 'capacity to engage emotionally with the world' might cover but which are not in question. First, there is our capacity to enjoy the non-doxastic emotions: hope, fear and their variants. Second, there are those simulacra of the doxastic emotions stimulated by reading novels and watching films or plays, emotions such as 'grief' and 'admiration' for the characters portrayed. ${ }^{19}$ Our life is surely enriched by our enjoyment of these psychological phenomena but I doubt we could engage emotionally with fiction without also having a general capacity to enjoy genuine admiration and grief. The latter capacity is closer to what I have in mind but acknowledging its value does not establish that knowledge as such is a good thing that, at least with regard to anything that matters to us, there is some value in knowing rather than remaining ignorant on that point. A specific piece of knowledge (such as knowledge of what has happened to my friend) enables me to engage emotionally with the fact known, to feel a range of doxastic emotions about it. We have reasons to value this specific topic-focused capacity and, I maintain, that is the ground of the value of particular items of knowledge.

This need to engage emotionally with particular facts is registered in the pain we feel when our emotions are baffled by ignorance, when we are rendered incapable of pride, shame, joy, grief and so forth because we know that we don't know the truth. It makes sense to want to know whether you were admired or despised by your long dead brother, whether you are soon going to 
die yourself and so forth, even if there is little you can or would wish to do about it. You want to know how you ought to feel about the past or the future; you want to be in a position to have feelings about it. A hedonist might respond that what you really want is to avoid the pain or distraction caused by ignorance but, if so, that could be achieved by popping a pill. Since the pill would not satisfy, the desire to know must be something more than the desire to avoid the psychic costs of ignorance. Rather it is a desire for some good whose absence is registered by these costs. It is also something more than the need for good news rather than bad. Of course, you want it to be the case that your brother admired you and that you'll lead a long and happy life. But, quite apart from that, you have some desire simply to know where you stand (and for its own sake).

These facts may seem puzzling. To know that my friend has died is to be placed in a situation in which a feeling of devastation is apt or even required of me and my life goes much worse should I feel an apt devastation rather than a quite inapt indifference. So why should anyone wish (for my sake) that I know whether my friend has died, when this knowledge will require me to feel devastated? Why should anyone wish that I be subject to a norm that I can comply with only at great cost to myself? The worry is not just that the benefits of knowledge will be outweighed by the costs, that I would on the whole be better off were I to remain blissfully ignorant of my friend's death. (This may or may not be the case). The worry is rather that, at least if the intrinsic value of knowledge lies in its emotional significance, knowing here lacks all intrinsic value because to know is to be required to have a feeling that there is no (non-instrumental) good in having. Since feeling devastated as such has no advantages over feeling peace of mind, how can knowledge derive its value from the fact that it requires this of us?

The puzzle comes from assuming that human interests make sense of normativity in one way only, namely where it can be shown that it is good for us to conform to the norms in question. Suppose instead that human beings have normative interests, that amongst the basic goods of human life are normative phenomena themselves: standards of aptness and appropriateness, obligations and permissions and so forth. Note the good here lies not in conformity to the norm in question, in having apt rather than inapt feelings. Rather, we are supposing, the good thing is being subject to the norms, is being held to the standard they set. That is how a psychological state can derive its value from the fact that it subjects us to certain norms, even though conformity with those norms may have nothing to be said for it.

In this regard, there is nothing unusual about knowledge (or belief). I would argue that friendship itself derives its value in part from the fact that it subjects friends to certain norms, even though conformity with those norms may do them no good whatsoever. Most writers agree that having friends is good for you and not just because friends provide you with help and support. Friendship is good for its own sake and thereby enriches your life. One prom- 
inent feature of friendship is that it brings into play a whole set of norms. Becoming John's friend changes the normative situation between us, creating reciprocal rights and obligations and altering what feelings are appropriate or even required of us. It is once John has become a good friend that I should be devastated by his death. Knowledge is like friendship in that it ensures that I am required to be devastated by John's death.

What attitude should I adopt towards the norm of friendship that requires me to feel devastated should John die? I might regard this norm as an unfortunate aspect of an otherwise good thing, a feature perhaps inextricably bound up with the depth of our friendship but not itself making any positive contribution to its value. Were that my attitude, I might well regret that my friendship with John would require me to feel devastated should he die. But isn't regret an inappropriate reaction to the realization that I am so required? Wouldn't it show that I failed to value the friendship and the bonds of loyalty it involves correctly? Not that I should feel glad when this norm comes into play because John does die. Here I am aptly sorry not just for John but also for myself and others would surely pity me. What I should not regret is the prior fact that, because of our friendship, I would be required to feel this way should John die. On the contrary that normative fact is part of the good of friendship: friendship serves our interest in being subject to such norms [Owens (2012), pp. 111-17].

My hypothesis is that knowledge is valuable for its own sake because knowledge serves a normative interest, namely our interest in being subject to certain norms of emotional aptness. Some of these interests come into play in special contexts like that of friendship. Others have wider application, like my interest in being able to engage emotionally with the fact that I have won a certain prize. Unless we know the relevant facts, we are not subject to these norms i.e. we are not emotionally engaged with the relevant subject matter and the value of knowledge lies in making this connection. By explaining where the value of knowledge lies, we have thereby established the authority of the Knowledge norm and thus of the epistemic norms that we must satisfy in order to attain knowledge. I'll conclude the paper by considering four objections to our account of the value of knowledge.

First, one may wonder whether the above line of thought really establishes the value of knowledge (over ignorance) rather than that of belief (over agnosticism). True I can't be proud of having won the prize unless I know that I won the prize but I can feel pride in the belief that I won the prize without knowing that I won it. Whether or not this belief constitutes knowledge, it still gives me the capacity to engage emotionally with an (apparent?) fact about myself, a capacity that is quite distinct from my capacity to engage emotionally with an acknowledged fiction like a play or a film. To form the belief that I won is to subject myself to various norms of evidence etc., norms to which I must subject myself if I am to be in a position to react with pride 
(and so forth) to my win. And if the latter capacity has a value that the capacity to engage with films and fiction lacks then I have an interest in entering a psychological state that is subject to the norms that govern belief formation. Why should we suppose that I have any further interest in the sort of emotional engagement with the world that requires knowledge of it?

I agree that belief may be better for me than mere agnosticism for the very reason just given and whether or not that belief constitutes knowledge. This result would underwrite much of the argument of this paper, grounding the authority of norms of belief formation in a value, namely the value of the capacity to enjoy doxastic emotion. But it may still be the case that one is better off knowing than merely believing and that this is so even when one's belief is true and entirely justified. I sensibly regret the fact that, as it turned out, I formed the true belief that I'd won the prize on the basis of someone's plausible but unreliable testimony. I'd prefer that my reaction be based on knowledge rather than ignorance.

Second, it may be objected there are many matters about which we form beliefs that are of no emotional significance to us. Yet if the Knowledge norm is valid, it applies equally to all beliefs. Pragmatists often hear the analogous complaint that a belief is subject to norms like Knowledge whether or not that particular belief is of any practical significance, whether or not there is any question of our acting successfully or otherwise on it. Both objections are based on a misconstrual of the relevant claims. The Pragmatist is asking after the function of belief. He is looking for a value served by Belief, a value that explains why we form beliefs. He need not argue that every single belief serves the function of Belief, only that beliefs as such (together with their characteristic norms) would not be a feature of human life unless at least some beliefs performed that function. I would make the same reply. True, a belief is subject to norms like Knowledge whether or not its subject matter has any emotional significance for us. But that fact is perfectly consistent with the idea that the function of Belief (and thus the source of the authority of its norms) lies in the contribution Belief makes to our emotional lives.

My case against Pragmatism did not rest on the fact that beliefs devoid of practical significance remain subject to normative discipline. Rather my complaint was that the pragmatic hypothesis about the normative character of belief did not fit the actual content of epistemic norms (viz. the car and lottery cases). By contrast, the hypothesis that the function of belief is to inform our emotional life generates correct predictions about the content of these norms. Provided beliefs are always subject to the norms suggested by that function, our functional explanation of those norms is in no way undermined by the fact that beliefs are frequently (perhaps even most frequently) formed for some reason quite unrelated to belief's function [Owens (2012), pp. 143-5]. 
Third, isn't the value of knowledge, however understood, often outweighed by other values? Mightn't I be better off all things considered were I to remain ignorant of my friend's death, even if I do miss out on some valuable form of emotional engagement with the world? But the norms of belief formation surely apply to such cases as much as to those in which the balance of advantage lies with knowledge. So, it may be inferred, the intrinsic value that I have attributed to knowledge cannot be the source of the authority of our epistemic norms. The strictness of these norms remains to be explained.

This objection misconstrues the connection between normativity and value. Different values underlie different normative systems. Were these systems in competition with one another, there would be pressure to weigh the underlying values against one another to produce an overall verdict about what ought to happen. And such competition would be hard to avoid if we thought that the point of epistemic norms were to guide the process of belief formation by reference to the underlying value, that belief formation involved choosing which belief to form. But, as I've argued elsewhere, this picture of epistemic normativity should be rejected [Owens (2000), (2003)]. The norms determining the rationality of beliefs are not in competition with those that determine the rationality of actions intended to induce belief and so a given value can make sense of the former without also making sense of the latter.

Suppose I were deciding which beliefs to have hypnotically induced in myself in various circumstances. I might well determine that were my friend to die, I would be better off believing my friend to be alive rather than dead. That choice would be perfectly rational according to the norms of practical reason though the belief thereby induced would be quite irrational. But beliefs are not usually formed by means of such self-manipulations i.e. by a process of practical deliberation in which one weighs the value of various possible beliefs and induces the belief that seems best. Normal belief formation is governed by a different set of norms with a different rationale.

A final objection is that the model of belief sketched in this paper entails an unacceptable form of conventionalism about epistemic norms. It is certainly true that, on my functionalist model, a believer is someone who enjoys a psychological state that is subject to certain norms and that is subject to those norms in part because it tends to conform to those norms. The believer is a believer because they are held to those norms in both senses, because they are in a state whose function is to constitute knowledge, whose normative and psychological roles converge on knowledge. Epistemic norms can serve a normative interest of ours only if their validity makes some different to our lives, only if these norms have some social or psychological reality.

Belief is like friendship in that amongst the interests it serves are our normative interests, our interests in being subject to certain norms. For these norms to serve our interests, their validity must have some connection with 
what actually happens. How well our lives are going is a function of what happens or tends to happen and, if I am right, one way in which what happens or tends to happen affects our well-being is precisely by determining which norms apply to us. For example, the norms of friendship apply to us because friendship is a social reality: if John had no tendency to honour the norms of friend, if John felt no guilt and others felt no inclination to blame him should he be disloyal, then John would not be my friend and neither of us would be bound by the norms of friendship. And our lives go better because we are bound by the norms of friendship.

Not just any set of conventions has normative force: some socially sanctioned relationships generate no obligations (etc.) precisely because they serve no normative interest. Most of the forms of friendship familiar to us are good at least to some extent and so their constituent norms do bind once socially recognized. In the case of friendship, the norms in question are (in the broadest sense) conventional, that is they are constituted by the choices and practices of individuals and groups. But what actually happens can be linked to what ought to happen in other ways. I have been assuming that the normative and the psychological roles of belief are connected, that it is no coincidence that a state with certain characteristic causes and effects is governed by these norms and vice versa. We don't make this connection via conscious choice of what to believe. Rather some mechanism (innate or acquired) ensures that certain psychological states tend to be sensitive to evidence in a way required by epistemic norms. In virtue of its action, these states count as beliefs i.e, as states subject to the norms characteristic of belief. And the regulatory mechanism in question may be partially social.

It is a commonplace that the norms of friendship vary from culture to culture and that various forms of friendship, each with a rather different normative character, can be good in different ways. Something similar may be true of the norms governing belief. I doubt the amount of evidence required for knowledge varies greatly at a local level. Individuals don't get to choose what epistemic standard to attach themselves to in the way we get to choose amongst form of friendship. But it may well be that different cultures have different standards of evidential adequacy for belief, standards that regulate the mechanisms governing the formation of an individual's beliefs. And the resulting emotional psychologies may, in their different ways, be good for the people in question. Epistemic norms are, at least to this extent, a matter of convention. ${ }^{20}$

\author{
Department of Philosophy \\ University of Reading \\ Reading RG6 6AA, UK \\ E-mail:d.owens@reading.ac.uk
}


NOTES

${ }^{1}$ Correctness rules out at least some candidates for the role of belief. For instance, Bayesian degrees of confidence are not governed by Correctness. Your confidence in $\mathrm{p}$ is meant to reflect the level of evidence you have for $\mathrm{p}$ and so, unless that level of evidence is 1 , coherence requires you to have a reciprocal degree of confidence in not-p. By contrast a rational person will believe either p or believe not-p or believe neither [Ross and Schroeder (2012), pp. 17-9].

${ }^{2}$ Frege distinguished 'grasping that p' from 'judging that p' [Frege (1977), p. 7]. A rational subject can grasp the proposition that $\mathrm{p}$ whilst also grasping some propositions inconsistent with it. For example, either to wish or to imagine that p, one must grasp the proposition that $\mathrm{p}$ but one can wish or imagine inconsistencies without being subject to criticism as illogical. On the other hand to judge that $\mathrm{p}$ and judge that not-p is to violate a rule of logic; it is to make subscription to Correctness impossible.

${ }^{3}$ I'm skeptical of the idea that the subject's choices and intentions can ever determine to which norms a psychological state is subject and thus whether it counts as a belief [Shah and Velleman (2005), pp. 511-4].

${ }^{4}$ For doubts about whether true belief has any intrinsic value [see Raz (2012), pp. 41-7]. Some of Raz's doubts could be resolved by supposing that what is of value is not a mere match between representation and reality but a successful tracking of reality by our representations. Still this proposal would face an analog of the question to be raised below: how reliably must a given representation track reality for it to be a good belief?

${ }^{5}$ Might one characterise belief as thought entered into with the overriding goal of thinking that $\mathrm{p}$ only if $\mathrm{p}$ is true? This proposal falls foul of James' point. Were the overriding goal of the believer the avoidance of error, that would mandate a comprehensive agnosticism. We must weigh the need to avoid error against the need to acquire true beliefs.

${ }^{6}$ To suspect that $\mathrm{p}$ is not just to imagine or hypothesise that $\mathrm{p}$ [pace Shah and Velleman (2005), pp. 512, 517]. One can entertain and test the hypothesis that $p$ whilst having a completely open mind about whether $\mathrm{p}$ is true but if one suspects that p, one's mind is not entirely open.

${ }^{7}$ Writing about the value of knowledge often focuses on why knowledge should be valued over the sort of justified conviction one has in the cases of accidentally true belief described by Gettier. I'll briefly return to that question at the end of the paper. At this point, my concern is with why we should value representing the truth by means of a state that aspires to be knowledge (i.e. belief) rather than by means of one that does not (e.g. suspicion).

${ }^{8}$ Some of these writers may have regarded pragmatic conceptions of belief as an alternative to alethic conceptions of belief. I'll treat claims such as Pragmatism as supplementing rather than replacing a claim like Correctness or Knowledge. (Velleman argues that without an alethic component, we could not distinguish a belief from a fantasy and a desire from a wish [Velleman (2000), pp. 255-77]).

${ }^{9}$ [Harman (1986), pp. 38-42 and 46-9]. For a more recent statement of the point, see Ross and Schroeder (2012), pp. 27-8.

${ }^{10}$ It should be noted that 'all-out' attitudes like belief and intention can be stronger or weaker, more or less firm. What makes these attitudes 'all-out' is the presence of a line between believing and not-believing, intending and not-intending. The 
strength of the attitude is a function of how easy it is to get the subject to cross the line and abandon the relevant belief or intention [Owens (2000), pp. 142-5].

${ }^{11}$ A similar example is used in support of this very conclusion by Fantl and McGrath (2007), p. 560.

12 Something like Default Pragmatism (though not under that name) is defended in Ross and Schroeder (2012), pp. 8-10 and 19-22.

13 [Descartes (1985), pp. 122-6]. For more on this point, see Owens (2007), pp. $172-5$.

${ }^{14}$ I can be in an irascible mood without there being any such proposition but that just means that I have a marked tendency to become angry.

${ }^{15}$ Unger (1975), pp. 189-96, argues that unless we can endorse the subject's claim to know the propositional object of their anger, we'll have a hard time characterizing the content of their emotion i.e. formulating a suitable propositional complement.

${ }^{16}$ Though my discussion of doxastic and non-doxastic emotion is greatly indebted to Gordon (1987), Chapter 2, I have not adopted his terminology. Gordon describes anger etc, as factive emotions. A factive verb is one that applies only where its propositional complement is true and this condition fails to capture the connection to knowledge. For example, 'guess' can be used as a factive verb - so you can't guess that $\mathrm{p}$ unless $\mathrm{p}$ is true - but guessing that $\mathrm{p}$ still excludes knowing that $\mathrm{p}$. Gordon calls the non-factive emotions 'epistemic emotions' a label that is better suited to his 'factive' emotions.

${ }^{17}$ Similarly the fear that you'll lose involves the suspicion that you'll lose as well as the wish that you won't.

${ }^{18}$ The notion of a 'slight doubt' is in any case problematic. In the eyes of Pragmatist, one who checks his car should have altogether abandoned the belief that his car is properly parked, at least for now, whilst in the eyes of the Default Pragmatist he need not have abandoned this belief at all.

${ }^{19}$ Walton argues that we do not really pity or admire characters in novels because the psychological states produced by novels lack the motivational force of genuine pity or admiration [Walton (1993), pp. 195-204]. In fact, as Velleman points out, wishes and fantasies play a motivational role analogous to belief and desire and the same is true of emotions based on wishes and fantasies. So the difference between real pity and the pity stimulated by novels must instead lie the latter's failure to be subject to a norm like Correctness or Knowledge [Velleman (2000), p. 270].

${ }^{20} \mathrm{I}$ am grateful for helpful reactions to audiences at a workshop on the "The Nature of Belief' organized by Joseph Raz at Columbia University and a workshop on 'Knowledge, Evidence and Practice' organized by Pascal Engel at the University of Geneva. Many thanks also to Alex Gregory, Nishi Shah, Matthew Silverstein, Sharon Street, David Velleman and Jose Zalabardo for comments on written drafts.

\section{REFERENCES}

Craig, E (1990), Knowledge and the State of Nature, Oxford, Oxford University Press.

Descartes, R. (1985), The Philosophical Writings of Descartes Volume 1, Cambridge, Cambridge University Press. 
— (1984), The Philosophical Writings of Descartes Volume 2, Cambridge, Cambridge University Press.

FANTL, J., and McGrath, M. (2007), 'On Pragmatic Encroachment in Epistemology', Philosophy and Phenomenological Research 75 (3), pp.558-89.

Frege, G. (1977), Logical Investigations, Oxford, Blackwell.

GoRDON, R. (1987), The Structure of Emotion, Cambridge, Cambridge University Press.

Harman, G., (1973), Thought, Princeton, Princeton University Press.

- (1986), Change in View, Cambridge, MIT Press.

HAWTHORne, J. (2004), Knowledge and Lotteries, Oxford, Oxford University Press.

HaWthorne, J. and StAnley J., (2008), 'Knowledge and Action', Journal of Philosophy 105 (10), pp. 571-90.

Hume, D. (1975), Enquiry Concerning Human Understanding, Oxford, Oxford University Press.

James, W. (1956), 'The Will to Believe' in his The Will to Believe, New York, Dover.

OwENs, D. (2000), Reason Without Freedom, London, Routledge.

- (2003), 'Does Belief Have An Aim?', Philosophical Studies 115, pp. 283-305.

- (2007), 'Descartes's Use of Doubt', Broughton, J. and Carriero, J. (eds.), A Companion to Descartes, Oxford, Blackwell, pp. 164-178.

- (2012), Shaping the Normative Landscape, Oxford, Oxford University Press.

RAZ, J. (2012), From Normativity to Responsibility, Oxford, Oxford University Press.

Ross, J. and Schroeder M. (2012), 'Belief, Credence and Pragmatic Encroachment' Philosophy and Phenomenological Research doi:10.1111/j.1933-1592.2011.00552.x.

Shah, N. and Velleman, D. (2005), 'Doxastic Deliberation', Philosophical Review 114 (4), pp. 497-534.

Unger, P. (1975), Ignorance, Oxford, Oxford University Press.

Velleman, D. (2000), The Possibility of Practical Reason, Oxford, Oxford University Press.

Walton, K. (1990), Mimesis as Make-Believe, Cambridge MA, Harvard University Press. 